\title{
Comparison of Traffic Speed Before, During and After "Banci Lalu Lintas" at Federal Road ft005
}

\author{
R. Rahman ${ }^{1,}$, , M. S. Nemmang ${ }^{1}$, N. A. Nazimuddin ${ }^{1}$, and Hazrul Abdul Hamid ${ }^{1}$ \\ ${ }^{1}$ Department of Infrastructure and Geomatic Engineering, Universiti Tun Hussein Onn Malaysia, \\ Johor, Malaysia
}

\begin{abstract}
Traffic engineering uses engineering methods and techniques to achieve the safe and time efficient movement of people and goods on roadways and it depends on traffic flow. The three main parameters of a traffic flow are volume, speed and density. Speed is an important transportation consideration because it relates to safety, time, comfort, convenience, and economics. This study is to show the difference of traffic speed for before, during and after a primary traffic survey called "Banci Lalu Lintas". This study also is conducted at Federal Road FT005 with collaboration of Jabatan Kerja Raya (JKR). In achieving the goal for this study, traffic speed is recorded by using two methods which are manual method and Automatic Traffic Count (ATC). For before and after the survey, manual method is used and the data is collected for 15 minutes, while during the survey, ATC is used in collecting data for 24 hours per day in a week. The data obtained where the mean speed is recorded and is compared as well as analyzed between three categories which are before, during and after "Banci Lalu Lintas" and using statistical analysis. In result, the speed of vehicles for during the survey is the lowest compared to before and after survey where the differential percentage are $6.68 \%$ and $23.64 \%$ for before - during and during - after "Banci Lalu Lintas". The study concluded that drivers tend to decrease their vehicles speed when there is an event or unexpected conditions on the road. The result is important for future development and safety of road in Malaysia.
\end{abstract}

\section{Introduction}

Seeing people rushing to run errands, and going to work during the day are normal sight in this modern era. To cope with time, majority of people chose to drive their own vehicle rather than using public transportation or walking. This is because, most people are not very satisfied with the services of public transportation as mentioned in [1]. Basically, speed is an important transportation consideration because it relates to safety, time, comfort, convenience and economics. This is because, most of the drivers have different perceptions of appropriate operating speed on the roads as suggested in [2]. Other than that, in [3] that studies the accidents behaviour stated that the increase of speed and access point would trigger an increase in the frequency of road accidents. Therefore, the transportation system

*Corresponding author: raha@uthm.edu.my 
offers a good speed, and majority of them using it as much as possible, then the best enemy of speed which is congestion will occur. A road system should be able to occupy the number of vehicles with the road condition so that drivers will maintain their speed and congestions can be reduced.

In Traffic Engineering, traffic flow is the study of the movement of vehicles at a given point in a given time. To better represent traffic flow, there are three vital elements that should be considered in traffic flow which are speed, density and volume. In this study, it is concentrate more on speed. In [4] defined as a rate of motion expressed as distance per unit of time, generally as Kilometres per hour $(\mathrm{km} / \mathrm{hr})$. At the point where the measurement of speed is taken, various vehicles that passes the point will be travelling at their own different speeds. Therefore, this study used 2 types of method in collecting data which are manual traffic count and automatic traffic count (ATC). ATC data is used for a variety of purposes to support transport planning and design considerations. It is a highly cost effective method of collecting large volumes of a week or more of classified and/ or speed data. ATC are normally identified as two rubber tubes laid across the carriageway linked to a road side recorder box. These tubes can measure both speed and number of vehicle movements and in some cases the weight of vehicles passing over. Besides that, manual traffic count needed a human effort in collecting data. In the end of this studies, the data collected have been compared which are before, during and after survey to get the result which are the speed differences on that three (3) times. Thus, the average speed of vehicles is recorded because it is almost impossible to track every vehicle speed on roadway.

\section{Literature review}

Speed is a primary factor in all modes of transportation and it is very important factor in the geometric design of roads. According to [5], the speed of vehicles on a road depends on the capabilities of the drivers and their vehicles, upon general conditions such as the physical characteristics of the road, the weather, the presence of other vehicles and the legal speed limitations.

The available sight distance on a roadway should be sufficiently long to enable a vehicle traveling at or a near the design speed to stop before reaching a stationary object in its path. To allow drivers to perceive, react, and safely stop, a minimum stopping sight distance must be available. In [6] stated that stopping sight distance can be defined as the following sum of two distances, reaction distance, where the distance traversed by the vehicle from the instant the driver sees an object necessitating a stop to the instant the brakes are applied. Braking distance, where the distance needed to stop the vehicle from the instant brake application begins.

Speed has been identified as a key risk factor in road traffic injuries, influencing both the risk of a road crash as well as the severity of the injuries that result from crashes [7]. Excess and inappropriate speed are responsible for a high proportion of the mortality and morbidity that result from road crashes. According to [8], speed reduction will be occurring due to the changing of road segment or have some event on the road segment and it will lead to the traffic shock wave.

\section{Method and data collection}

This study was conducted at KM24 Jalan Batu Pahat-Pontian FT005 as shown in Fig.1. Data is collected for before, during and after "Banci Lalu Lintas". For before and after, manual method is used while for during, Automatic Traffic Count is used as shown in Fig. 2. For manual method which are manual observation and using manual counter, the data is 
collected for 15 minutes in the evening based on previous year of "Banci Lalu Lintas" traffic volume data as the peak hour determination. For the other method which is by using ATC, the data is collected within 24 hours for one-week period and the determination of specific time for peak hour can be obtained by taking the highest traffic volume from the survey data for during "Banci Lalu Lintas". Fig 3(a) shows the visualization of equipment setup and Fig. 3(b) show the length between port A and port B for the installation of ATC. Both of this method have collected traffic speed that passed through the road but the best. Later the data collected were analyzed to compare by using statistically analysis.

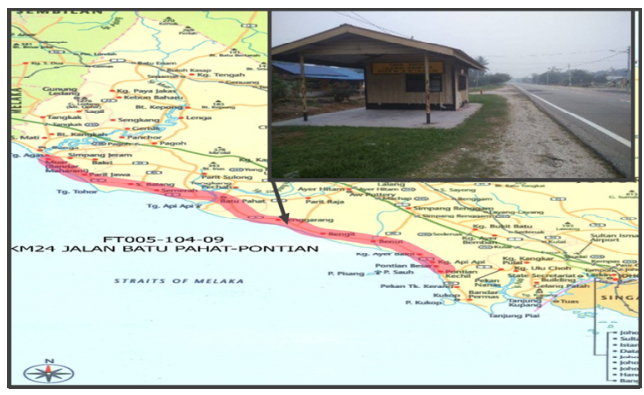

Fig. 1. Site Location at KM24 Jalan Batu Pahat - Pontian and Census Station JR112.

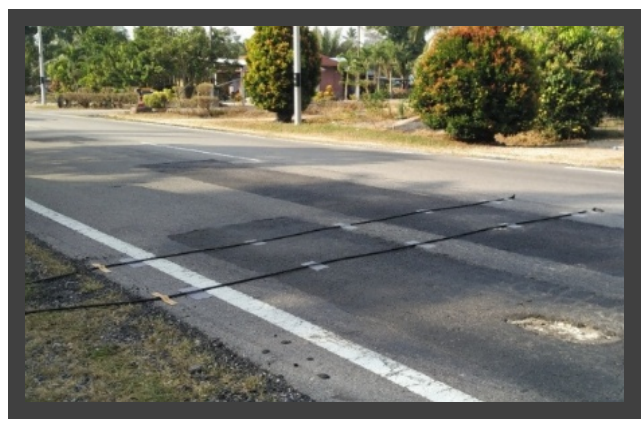

Fig. 2. Pneumatic Road Tube Installation.
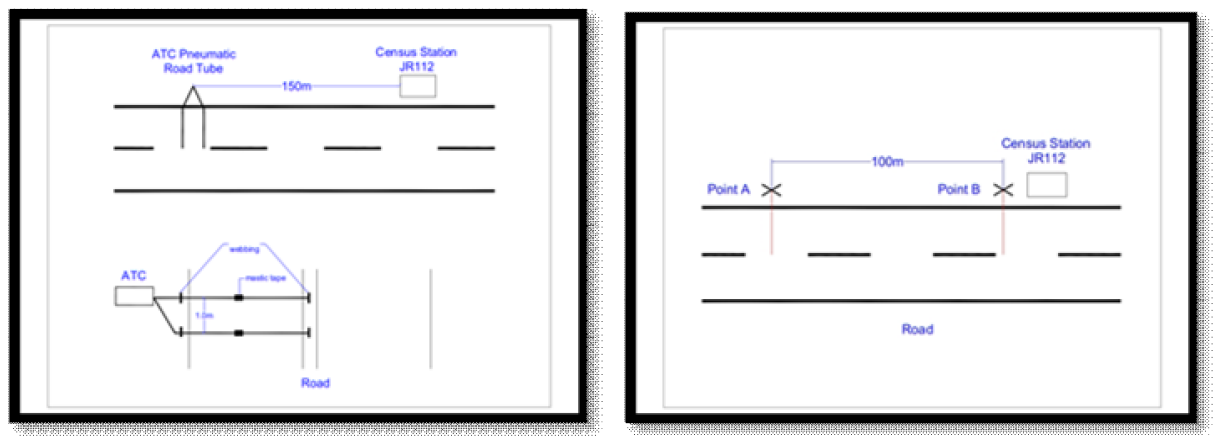

Fig. 3(a). Layout Plan for ATC and Manual Method Speed Data Collection
Fig. 3(b). Length between port A and port B for the installation of ATC 


\section{Result and analysis}

In result, this study will indicate the difference of traffic speed for before, during and after "Banci Lalu Lintas" as in Table 1.

Table 1: Traffic volume and speed for before, during and after survey

\begin{tabular}{|c|c|c|c|}
\hline Categories & Before Survey & During Survey & After Survey \\
\hline Average Speed (km/hr) & 71 & 66 & 84 \\
\hline Traffic Volume & 94 & 131 & 86 \\
\hline
\end{tabular}

While in Fig. 4 below illustrated that traffic speed during "Banci Lalu Lintas" is the lowest than the other two categories where the percentage are $6.68 \%$ and $23.64 \%$ for before - during and during - after "Banci Lalu Lintas". This has proved that drivers will reduce their speed when they sees any event beside the roads which are people wearing the safety jacket and focusing on the vehicle movement on the road.

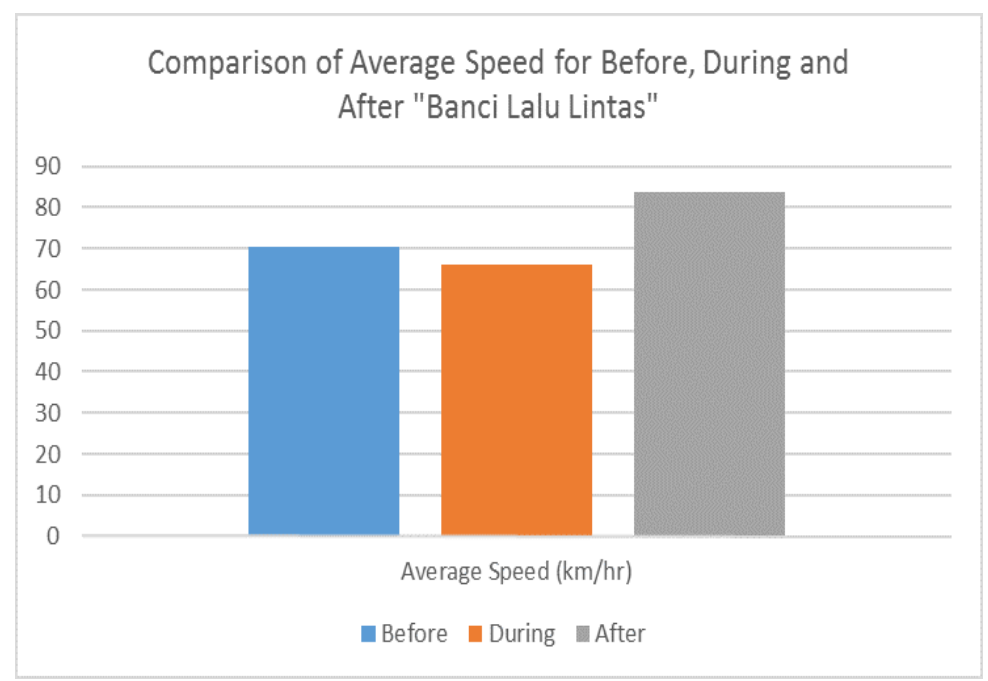

Fig. 4. Comparison of average speed for before, during and after survey

As in Table 2, for the During-After and Before-After "Banci Lalu Lintas", P-value calculated is 0.0002 and 0.0004 which both of these value are $<0.05$, thus the null hypothesis is rejected which "there are significant differences". While for the BeforeDuring "Banci Lalu Lintas", P-value calculated is $>0.05$, thus the null hypothesis is accepted. From this result, there are differences in the traffic average speed data collection between the During-After and Before-After "Banci Lalu Lintas", unlike Before-During "Banci Lalu Lintas".

However, "Banci Lalu Lintas" only conducted for 16 hours per day in a week, starting at $6 \mathrm{am}$ until $10 \mathrm{pm}$, after 16 hours, drivers no longer aware about their speed which leads them to increase the speed since there is no one in the census station or any other traffic speed traps. It has been shown in Table 3 and Fig. 5 that the vehicles speed for after 16 hours, Wednesday 6th April 2016. 
Table 2. P-value for two-sample t-test in respect to categories of "Banci Lalu Lintas"

\begin{tabular}{|c|c|}
\hline Categories of "Banci Lalu Lintas" & P - value \\
\hline Before - During & 0.91 \\
\hline During - After & 0.0002 \\
\hline Before - After & 0.0004 \\
\hline
\end{tabular}

Table 3. Traffic mean speed at $11 \mathrm{pm}$ to $5 \mathrm{am}$ for Tuesday - Wednesday.

\begin{tabular}{|c|c|c|c|c|c|c|}
\hline \multicolumn{7}{|c|}{ Tuesday, April 5, 2016 } \\
\hline Time & $\begin{array}{c}\text { Traffic } \\
\text { volume }\end{array}$ & $\begin{array}{c}\text { Mean } \\
\text { speed }\end{array}$ & $\begin{array}{c}\mathbf{8 5}^{\text {th }} \text { percentile } \\
\text { speed }\end{array}$ & $\begin{array}{c}\text { Minimum } \\
\text { speed }\end{array}$ & $\begin{array}{c}\text { Maximum } \\
\text { speed }\end{array}$ & $\begin{array}{c}\text { Mean speed } \\
\text { exceeding 90 }\end{array}$ \\
\hline 2300 & 139 & 74 & 94 & 28.4 & 133 & 105 \\
\hline \multicolumn{7}{|c|}{ Wednesday, April 6, 2016 } \\
\hline 0000 & 81 & 78.9 & 98.3 & 47.2 & 128.4 & 103 \\
\hline 0100 & 42 & 75.1 & 89.6 & 30.5 & 130.4 & 109.4 \\
\hline 0200 & 44 & 75.2 & 89.3 & 24.3 & 129.3 & 110 \\
\hline 0300 & 23 & 72.8 & 95.4 & 26.8 & 125.6 & 106.8 \\
\hline 0400 & 17 & 75.2 & 96.1 & 38.3 & 110.4 & 100.6 \\
\hline 0500 & 52 & 79.7 & 99.7 & 43.1 & 132.1 & 105.6 \\
\hline
\end{tabular}

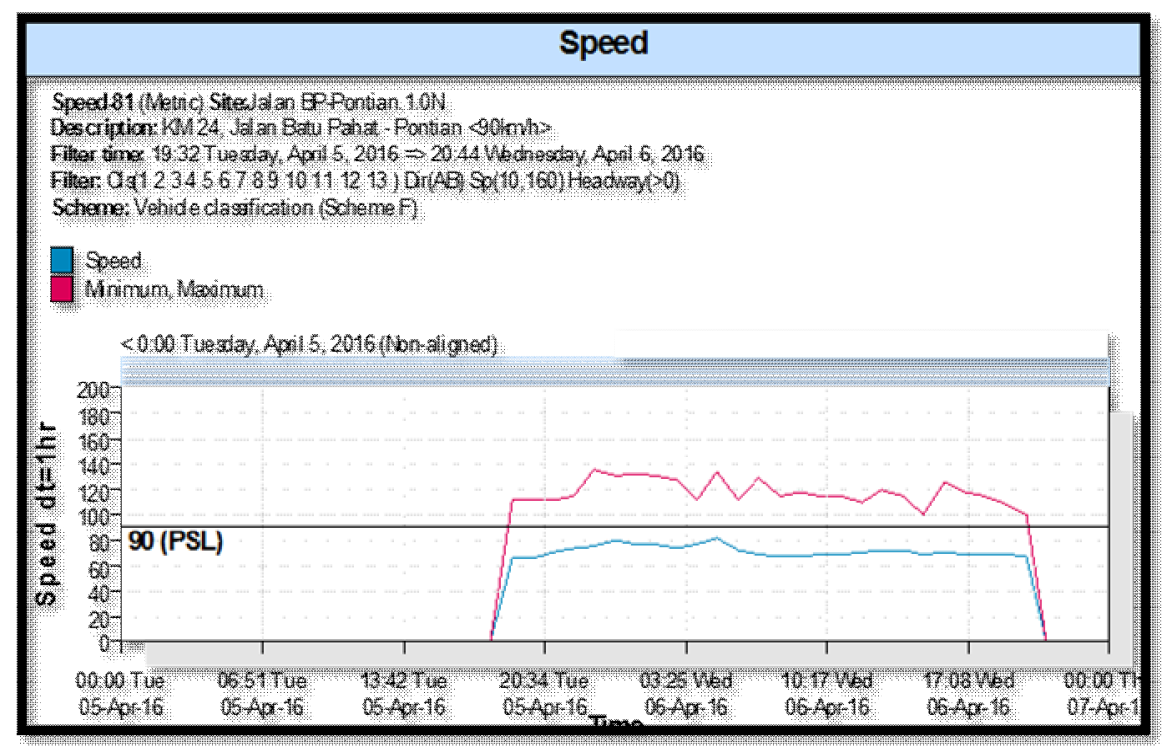

Fig. 5. Traffic speed after "Banci Lalu Lintas" conducted for Tuesday - Wednesday

The result can be concluded that the study has achieved the two objectives. The traffic speed will change either increase or decrease due to the event/activity at the location. From the data obtained, the speed is decreased during the survey while before and after the survey, it increased. Traffic speeding will leads to accident which can be proved by the past years data accident. Fig. 6 below is the graph of accidents and casualty at FT005 from 2007 to May, 2010 as stated in [9]. It indicated that the total number of accidents recorded at this 
route is 2774 cases as it increased every year. Thus, it is shown that the number of cases is high for within 3 years. Therefore, it shows that the driver were tend to speeding during driving in this road.

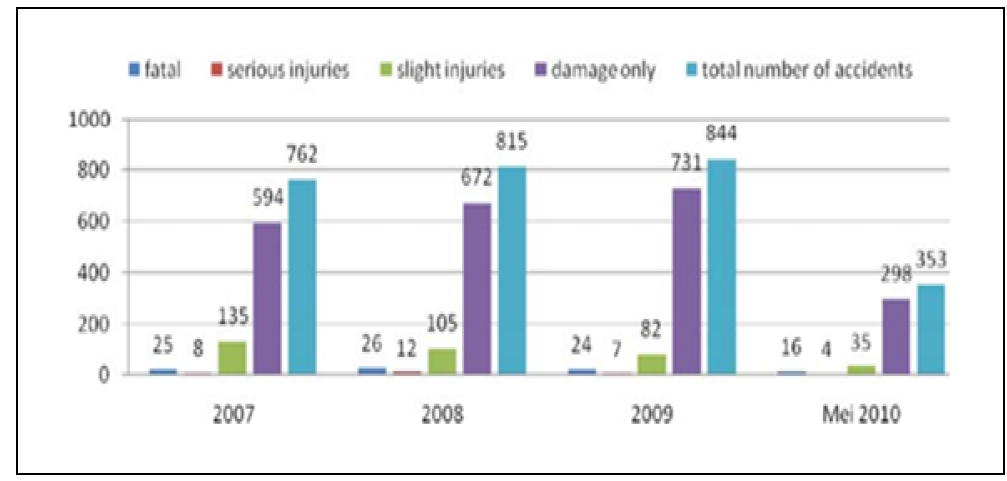

Fig. 6. Accidents and Casualty at FT005 for 2007 until May, 2010 (Source: [10])

\section{Conclusion}

This study is considered successful since the two objectives has been achieved as there are differences of traffic speed for before, during and after "Banci Lalu Lintas" which is conducted at KM24 Jalan Batu Pahat - Pontian within a week observation by using ATC and 15 minutes by using manual method. The results have been proven that during "Banci Lalu Lintas", the speed of vehicles decreased compared to before and after "Banci Lalu Lintas" where the percentage are $6.68 \%$ and $23.64 \%$ for before - during and during - after "Banci Lalu Lintas". In conclusion, research obtained that drivers were aware of their speed when there is an event or unexpected conditions for instance "Banci Lalu Lintas" that make them following the rules.

This research is supported by the Short Term Grant (STG) of Universiti Tun Hussein Onn Malaysia (UTHM) in Vot U341.

\section{References}

[1] R. Ismail, M.H. Hafezi, R.M. Nor, and K. Ambak, Passengers preference and satisfaction of public transport in Malaysia Sustainable Urban Transport Research Centre ( SUTRA ), Department of Civil and Structural, Aust. J. Basic Appl. Sci., 6, 410-416 (2012)

[2] B.D. Daniel, N. Alan, and G. Koorey, Investigating speed patterns and estimating speed on traffic-calmed streets, IPENZ Transp. Gr. Conf. Auckl. March, (2011).

[3] M.I. Masirin, W.A. Al-bargi, J. Prasetijo, and B.D. Daniel, Road accident analysis: A case study of federal route, MATEC Web Conf., 4, 1-7 (2016)

[4] Transportation Research Board, National Research Council, Highway Capacity Manual, Washington, (2000)

[5] R. Branch, Arahan Teknik Jalan 8/86 (Pindaan 2015), A Guide on Geometric Design of Roads, Public Works Department Malaysia, Kuala Lumpur, (2015)

[6] American Association of State Highway and Transportation Officials, A Policy on Geometric Design of Highways and Streets, Washington, (1994)

[7] M. Idrus, M. Masirin, and N.A. Mohamad, Analysis of road infrastructural audit along jalan Batu Pahat-Kluang Malaysia : A case study, International Integrated Engineering 
Summit, 1-7 (2014)

[8] R. Rahman, Extent of traffic kinematic waves and queuing caused by midblock u-turn facilities, Proceedings of the ITRN2012, (2012)

[9] C. Norbalkish, I. Yusof, M. Erwan, Report of Prediction of Accident Trend at TwoLane Federal, 178-190,Universiti Tun Hussein Onn Malaysia, (2011)

[10] Royal Malaysian Police, Accidents and Casualty at FT005 for 2007 until May, Kuala Lumpur, (2010) 